\title{
A new era in the discovery of de novo mutations underlying human genetic disease
}

\author{
Chee-Seng $\mathrm{Ku}^{1 *}$, Vasilis Vasiliou ${ }^{2}$ and David N Cooper ${ }^{3^{*}}$
}

Keywords: de novo mutation, Exome sequencing,

Human disease

\section{Editorial text}

Germline mutations arise anew during meiosis in every generation. Such spontaneously occurring genetic alterations are termed de novo mutations and serve to describe those heritable mutations that neither parent possessed or transmitted. Thus, de novo mutations denote mutations that arose in the gametes of the parents as distinct from post-zygotic somatic mutations that arise during embryonic development. Studies of de novo mutations in the human genome have been very challenging owing to past technological limitations. However, the advent of highthrough put next-generation sequencing (NGS) technologies has ushered in a new era in the study of de novo mutations. Whole-genome sequencing (WGS) and whole-exome sequencing (WES) can now be performed on parentoffspring trios to identify de novo point mutations in the entire genome or within protein-coding regions, respectively [1-3]. Although genome-wide de novo copy number variants (CNVs) were previously studied using microarrays [4-7], the study of de novo point mutations or single nucleotide variants (SNVs) required the advent of largescale sequencing, which was not feasible using Sanger sequencing [1-3]. As with inherited mutations, de novo mutations range in size from point mutations and small indels of multiple bases to much larger CNVs and structural rearrangements [8]. In this article, we focus on de novo point mutations/SNVs and their implications for our understanding of the etiology of common complex diseases as well as rare Mendelian diseases.

The availability of NGS has allowed first estimations of the human genome mutation rate as well as a glimpse of

\footnotetext{
* Correspondence: cheeseng.ku@ki.se; cooperDN@cardiff.ac.uk

'Department of Medical Epidemiology and Biostatistics, Karolinska Institutet, Nobels väg 12B, Stockholm SE-171 77, Sweden

${ }^{3}$ Institute of Medical Genetics, Cardiff University, Heath Park, Cardiff, Cardiff CF14 4XN, UK

Full list of author information is available at the end of the article
}

the spatial distribution of de novo point mutations in the human genome and their association with heritable diseases [1-3,9-13]. Recent studies have estimated the pergeneration mutation rate in humans as approximately $10^{-8}$. For example, sequencing the complete genomes from two parent-offspring trios (from the HapMap CEU and YRI, to $>22$-fold mapped depth) identified a total of 49 and 35 germline de novo point mutations in the two trios, respectively [2]. Similarly, an average de novo mutation rate of $1.20 \times 10^{-8}$ per nucleotide per generation was also reported by sequencing the entire genomes of 78 Icelandic parent-offspring trios [3]. Interestingly, the diversity in the mutation rate of SNVs was found to be strongly influenced by the age of the father when the child was conceived (the impact of paternal age corresponds to about two mutations per year). These findings have highlighted the likely importance of the father's age for the risk of those diseases which appear to be strongly affected by de novo mutations, e.g., schizophrenia and autism (see below) [3]. However, the mutation rate is critically dependent upon the type of mutation being considered, as the $\mathrm{CNV}$ mutation rate is somewhat higher than the single base-pair substitution mutation rate [14].

Owing to technical limitations, the contribution of de novo point mutations to human genetic diseases (both common complex disease and rare Mendelian disorder) has remained largely unexplored. De novo point mutations are nevertheless likely to have severe biological or phenotypic consequences when they impact functionally important nucleotides in the genome (for example, nonsense mutations or missense mutations in evolutionarily conserved regions). However, only a relatively small proportion of the de novo point mutations occurring at each meiosis will alter functionally important nucleotides [1-3]. Although de novo CNVs have been shown, using whole-genome genotyping arrays, to be associated with 
several common neurodevelopmental diseases such as schizophrenia and autism [4-7], it was not until very recently that de novo point mutations were also implicated in the etiology of schizophrenia, autism, and mental retardation through the WES of affected trios [9-12,15-17]. In similar vein, de novo point mutations have also been found to be responsible for sporadic cases of various rare dominant Mendelian disorders such as Kabuki syndrome, Schinzel-Giedion syndrome, and Bohring-Opitz syndrome [18-20]. These Mendelian disorders are also characterized by multiple neurodevelopmental defects; thus, for example, Bohring-Opitz syndrome is a clinically recognizable syndrome characterized by severe intellectual disability, distinctive facial features, and multiple congenital malformations [20].

It has been postulated that the occurrence of de novo mutations might explain why diseases characterized by dramatically reduced fecundity such as mental retardation and schizophrenia nevertheless remain frequent in the population. If this were indeed to be the case, the de novo mutations occurring in sporadic cases of these diseases would serve to replenish the number of highly penetrant disease mutations in every generation despite the continual negative selection. Indeed, de novo CNVs are a known cause of schizophrenia, autism, and mental retardation [21,22]. In addition, de novo point mutations have also been identified in schizophrenia through the WES of affected case-parent trios. In the exomes of 53 sporadic schizophrenia cases (with no history of the disease in a first- or second-degree relative), 22 unaffected controls and their parents were sequenced which led to the identification of a total of 34 de novo point mutations/SNVs and 4 de novo indels in the affected trios. However, it is noteworthy that some de novo SNVs (four non-synonymous and three synonymous) were also identified in the control subjects. This suggests that identifying the pathogenic and/or deleterious de novo mutations from a non-disease-associated mutational background may be a tricky task [11]. In a parallel development, de novo mutations were also found to be enriched in autism spectrum disorder (ASD)/autism [15-17]. A large WES study of 238 families from a comprehensively phenotyped ASD cohort comprising pedigrees with two unaffected parents and an affected proband (and in 200 families, an unaffected sibling) found that highly disruptive (nonsense and splice-site) de novo point mutations in brain-expressed genes were associated with ASDs and that these mutations carried large effects. De novo point mutations have also been identified in individuals with unexplained mental retardation [9]. These findings provide further support for the likely importance of de novo mutations in the etiology of these complex neurodevelopmental disorders.

De novo heterozygous point mutations are also believed to be a common cause of sporadic cases of those rare Mendelian diseases that are characterized by multiple congenital malformations or anomalies, developmental delay, and mental retardation or intellectual disability such as Schinzel-Giedion syndrome and Bohring-Opitz syndrome, the genetic basis of which had previously remained elusive $[19,20]$. These diseasecausing de novo mutations were undetected by linkage analysis because they were not transmitted between the generations. Although the conventional gene-centric approach of limited Sanger sequencing is capable of identifying de novo point mutations, this method cannot realistically be scaled up to encompass the entire genome, exome, or even all genes on a chromosomal arm. Further, it is a hypothesis-driven approach whereby the selection of candidate genes is highly dependent upon an a priori hypothesis which is in turn constrained by our still limited knowledge of the biological pathways that characterize the diseases in question. By contrast, WES constitutes a powerful and robust tool which can be used to unravel de novo point mutations by screening the entire coding region of the genome (i.e., all the exons) of the affected parent-offspring trios. The first success in identifying novel de novo mutations for rare diseases came with the identification of the MLL2 gene underlying Kabuki syndrome, even although this study did not adopt a trio design [18]. Instead, the exomes of unrelated probands from different families were sequenced in order to identify the causal genes, and in families where parental DNA was available, the mutations were confirmed to be de novo in some of them [18]. However, similar success was also obtained in studies that applied WES to affected trios for various rare diseases. Thus, de novo mutations in the EZH2 gene underlying Weaver syndrome [23] and in the $A C T B$ and ACTG1 genes underlying Baraitser-Winter syndrome were identified by means of WES of trios [24].

The advantage of applying WES to parent-case trios is that it narrows down the list of potential candidate disease mutations very considerably because of the limited number of de novo point mutations to be expected within protein-coding sequences. This is of course especially useful for disorders in which de novo mutations are strongly suspected, e.g., Baraitser-Winter syndrome (a rare but now well-defined developmental disorder). No familial recurrence or consanguinity has ever been observed in families affected with this syndrome; hence, the genetic basis of Baraitser-Winter syndrome was always likely to be due to the occurrence of de novo point mutations (as no pathogenic CNVs had been detected using microarrays) [24]. WES would be sufficient to identify the mutations underlying most rare Mendelian disorders as long as the causative mutations reside within the coding regions. In contrast to WGS, WES is more cost-effective and analytically less challenging. 
However, some studies have also applied the WGS approach, for example, to a family quartet affected by a sporadic case of severe epileptic encephalopathy. WGS of the family, containing an affected proband and her unaffected parents and sibling, revealed a de novo heterozygous missense mutation in SCN8A [25].

Although numerous de novo point mutations have now been identified which are responsible for rare disorders, it remains unclear what constitutes evidence for causality. It is both difficult and challenging to establish the causative role of newly identified mutations, even for de novo events. Co-segregation of the putative causal mutation with a disease phenotype in large pedigrees might provide strong genetic evidence of causality, but this would not be applicable in the case of de novo mutations which are, by definition, not transmitted through the generations. Therefore, for a newly identified putative pathological mutation which appears to have occurred de novo, further screening of additional cases is invariably required. Detection of recurrent mutation (or identical mutations) or different mutations in the same gene in additional cases and their absence in healthy individuals constitutes strong evidence of causality. However, it might be quite difficult, in the context of extremely rare disorders, to find additional cases with which to validate the newly identified de novo mutation. Although challenging, further validation in additional samples has generally been successful in recent WES studies of rare disorders. Most notably, after the discovery of de novo point mutations in ACTG1 and ACTB by WES of three parent-case trios with Baraitser-Winter syndrome, the study used Sanger sequencing to screen the coding sequence of both genes in 15 additional affected individuals and was successful in detecting pathogenic mutations in one or other of these genes in all subjects studied [24]. These mutations were then shown to have occurred de novo in all 11 subjects from whom parental DNA was available. Moreover, further validation in normal controls showed that none of the mutations identified in Baraitser-Winter syndrome were present in several large control datasets [24]. As an alternative, molecular functional studies to confirm the functional significance of newly identified de novo mutations could be considered confirmatory if and when the mutated gene had a clear role in conferring a welldefined molecular pathology.

The studies of de novo mutations that have been performed so far have adopted the WES approach. However, the current shortcoming of WES lies in its necessary focus on coding regions. Hence, the clinicobiological importance of de novo mutations in non-coding regions remains unclear. Although very challenging, WGS eventually promises to permit the comprehensive analysis of de novo mutations (and other inherited variants) in the human genome in collections of case-parent trios affected by various heritable diseases. Since a considerable number of inherited mutations for various diseases have now been found in non-coding regions [26], it is reasonable to suppose that this could also pertain in the context of de novo mutations within non-coding regions. This in turn supports the likely efficacy of a strategy of adopting WGS to ascertain the full impact of de novo mutations in human genetic disease and to study the molecular characteristics of such lesions. The collection of a large number of such trios would be important in this context. The discovery to date of de novo mutations underlying common complex diseases as well as rare Mendelian disorders is likely to represent only the tip of the iceberg; more discoveries would be anticipated in the near future.

\section{Competing interests}

The authors declared that they have no competing interests.

\section{Authors' contributions}

CSK and W contributed to the conceptualization of this article. CSK and DNC contributed to the writing of this article. W contributed to proofreading. CSK and DNC approved the final manuscript. All authors read and approved the final manuscript.

\section{Author details}

'Department of Medical Epidemiology and Biostatistics, Karolinska Institutet, Nobels väg 12B, Stockholm SE-171 77, Sweden. ${ }^{2}$ Department of Pharmaceutical Sciences, University of Colorado Anschutz Medical Campus, 12850 East Montview Blvd, Aurora, CO 80045, USA. ${ }^{3}$ Institute of Medical Genetics, Cardiff University, Heath Park, Cardiff, Cardiff CF14 4XN, UK.

Received: 13 October 2012 Accepted: 11 November 2012

Published: 12 December 2012

\section{References}

1. Roach JC, Glusman G, Smit AF, Huff CD, Hubley R, Shannon PT, Rowen L, Pant KP, Goodman N, Bamshad M, Shendure J, Drmanac R, Jorde LB, Hood $L$, Galas DJ: Analysis of genetic inheritance in a family quartet by whole-genome sequencing. Science 2010, 328:636-639.

2. Conrad DF, Keebler JE, DePristo MA, Lindsay SJ, Zhang Y, Casals F, Idaghdour Y, Hartl CL, Torroja C, Garimella KV, Zilversmit M, Cartwright R, Rouleau GA, Daly M, Stone EA, Hurles ME, Awadalla P, Genomes P: Variation in genome-wide mutation rates within and between human families. Nat Genet 2011, 43:712-714.

3. Kong A, Frigge ML, Masson G, Besenbacher S, Sulem P, Magnusson G, Gudjonsson SA, Sigurdsson A, Jonasdottir A, Jonasdottir A, Wong WS, Sigurdsson G, Walters GB, Steinberg S, Helgason H, Thorleifsson G, Gudbjartsson DF, Helgason A, Magnusson OT, Thorsteinsdottir U, Stefansson $K$ : Rate of de novo mutations and the importance of father's age to disease risk. Nature 2012, 488:471-475.

4. Xu B, Roos JL, Levy S, van Rensburg EJ, Gogos JA, Karayiorgou M: Strong association of de novo copy number mutations with sporadic schizophrenia. Nat Genet 2008, 40:880-885.

5. Rees E, Moskvina V, Owen MJ, O'Donovan MC, Kirov G: De novo rates and selection of schizophrenia-associated copy number variants. Biol Psychiatry 2011, 70:1109-1114.

6. Kirov G, Pocklington AJ, Holmans P, Ivanov D, Ikeda M, Ruderfer D, Moran J, Chambert K, Toncheva D, Georgieva L, Grozeva D, Fjodorova M, Wollerton R, Rees E, Nikolov I, van de Lagemaat LN, Bayes A, Fernandez E, Olason PI, Bottcher Y, Komiyama NH, Collins MO, Choudhary J, Stefansson K, Stefansson H, Grant SG, Purcell S, Sklar P, O'Donovan MC, Owen MJ: De novo CNV analysis implicates specific abnormalities of postsynaptic signalling complexes in the pathogenesis of schizophrenia. Mol Psychiatry 2012, 17:142-153. 
7. Sanders SJ, Ercan-Sencicek AG, Hus V, Luo R, Murtha MT, Moreno-De-Luca D, Chu SH, Moreau MP, Gupta AR, Thomson SA, Mason CE, Bilguvar K, Celestino-Soper PB, Choi M, Crawford EL, Davis L, Wright NR, Dhodapkar RM, DiCola M, DiLullo NM, Fernandez TV, Fielding-Singh V, Fishman DO, Frahm S, Garagaloyan R, Goh GS, Kammela S, Klei L, Lowe JK, Lund SC, et al: Multiple recurrent de novo CNVs, including duplications of the 7q11.23 Williams syndrome region, are strongly associated with autism. Neuron 2011, 70:863-885.

8. Cooper DN, Bacolla A, Ferec C, Vasquez KM, Kehrer-Sawatzki H, Chen JM: On the sequence-directed nature of human gene mutation: the role of genomic architecture and the local DNA sequence environment in mediating gene mutations underlying human inherited disease. Hum Mutat 2011, 32:1075-1099.

9. Vissers LE, de Ligt J, Gilissen $C$, Janssen I, Steehouwer M, de Vries P, van Lier B, Arts P, Wieskamp N, del Rosario M, van Bon BW, Hoischen A, de Vries BB, Brunner $\mathrm{HG}$, Veltman JA: A de novo paradigm for mental retardation. Nat Genet 2010, 42:1109-1112.

10. O'Roak BJ, Deriziotis P, Lee C, Vives L, Schwartz JJ, Girirajan S, Karakoc E, Mackenzie AP, Ng SB, Baker C, Rieder MJ, Nickerson DA, Bernier R, Fisher SE, Shendure J, Eichler EE: Exome sequencing in sporadic autism spectrum disorders identifies severe de novo mutations. Nat Genet 2011, 43:585-589.

11. Xu B, Roos JL, Dexheimer P, Boone B, Plummer B, Levy S, Gogos JA, Karayiorgou M: Exome sequencing supports a de novo mutational paradigm for schizophrenia. Nat Genet 2011, 43:864-868.

12. Girard SL, Gauthier J, Noreau A, Xiong L, Zhou S, Jouan L, Dionne-Laporte A Spiegelman D, Henrion E, Diallo O, Thibodeau P, Bachand I, Bao JY, Tong $\mathrm{AH}$, Lin CH, Millet B, Jaafari N, Joober R, Dion PA, Lok S, Krebs MO, Rouleau $G A$ : Increased exonic de novo mutation rate in individuals with schizophrenia. Nat Genet 2011, 43:860-863.

13. Scally A, Durbin R: Revising the human mutation rate: implications for understanding human evolution. Nat Rev Genet 2012, 13:745-753.

14. Itsara A, Wu H, Smith JD, Nickerson DA, Romieu I, London SJ, Eichler EE: De novo rates and selection of large copy number variation. Genome Res 2010, 20:1469-1481.

15. Neale BM, Kou Y, Liu L, Ma'ayan A, Samocha KE, Sabo A, Lin CF, Stevens C, Wang LS, Makarov V, Polak P, Yoon S, Maguire J, Crawford EL, Campbell NG, Geller ET, Valladares O, Schafer C, Liu H, Zhao T, Cai G, Lihm J, Dannenfelser R, Jabado O, Peralta Z, Nagaswamy U, Muzny D, Reid JG, Newsham I, Wu Y, et al: Patterns and rates of exonic de novo mutations in autism spectrum disorders. Nature 2012, 485:242-245.

16. Sanders SJ, Murtha MT, Gupta AR, Murdoch JD, Raubeson MJ, Willsey AJ, Ercan-Sencicek AG, DiLullo NM, Parikshak NN, Stein JL, Walker MF, Ober GT, Teran NA, Song Y, El-Fishawy P, Murtha RC, Choi M, Overton JD, Bjornson RD, Carriero NJ, Meyer KA, Bilguvar K, Mane SM, Sestan N, Lifton RP, Gunel M, Roeder K, Geschwind DH, Devlin B, State MW: De novo mutations revealed by whole-exome sequencing are strongly associated with autism. Nature 2012, 485:237-241.

17. O'Roak BJ, Vives L, Girirajan S, Karakoc E, Krumm N, Coe BP, Levy R, Ko A, Lee C, Smith JD, Turner EH, Stanaway IB, Vernot B, Malig M, Baker C, Reilly B, Akey JM, Borenstein E, Rieder MJ, Nickerson DA, Bernier R, Shendure J, Eichler EE: Sporadic autism exomes reveal a highly interconnected protein network of de novo mutations. Nature 2012, 485:246-250.

18. Ng SB, Bigham AW, Buckingham KJ, Hannibal MC, McMillin MJ, Gildersleeve HI, Beck AE, Tabor HK, Cooper GM, Mefford HC, Lee C, Turner EH, Smith JD, Rieder MJ, Yoshiura K, Matsumoto N, Ohta T, Niikawa N, Nickerson DA, Bamshad MJ, Shendure J: Exome sequencing identifies MLL2 mutations as a cause of Kabuki syndrome. Nat Genet 2010, 42:790-793.

19. Hoischen A, van Bon BW, Gilissen C, Arts P, van Lier B, Steehouwer M, de Vries $P$, de Reuver R, Wieskamp N, Mortier G, Devriendt K, Amorim MZ, Revencu N, Kidd A, Barbosa M, Turner A, Smith J, Oley C, Henderson A, Hayes IM, Thompson EM, Brunner HG, de Vries BB, Veltman JA: De novo mutations of SETBP1 cause Schinzel-Giedion syndrome. Nat Genet 2010, 42:483-485.

20. Hoischen A, van Bon BW, Rodriguez-Santiago B, Gilissen C, Vissers LE, de Vries P, Janssen I, van Lier B, Hastings R, Smithson SF, Newbury-Ecob R, Kjaergaard S, Goodship J, McGowan R, Bartholdi D, Rauch A, Peippo M, Cobben JM, Wieczorek D, Gillessen-Kaesbach G, Veltman JA, Brunner HG, de Vries BB: De novo nonsense mutations in ASXL1 cause Bohring-Opitz syndrome. Nat Genet 2011, 43:729-731.
21. Malhotra D, Sebat J: CNVs: harbingers of a rare variant revolution in psychiatric genetics. Cell 2012, 148:1223-1241.

22. Rodriguez-Murillo L, Gogos JA, Karayiorgou M: The genetic architecture of schizophrenia: new mutations and emerging paradigms. Annu Rev Med 2012, 63:63-80.

23. Gibson WT, Hood RL, Zhan SH, Bulman DE, Fejes AP, Moore R, Mungall AJ, Eydoux P, Babul-Hirji R, An J, Marra MA, Consortium FC, Chitayat D, Boycott KM, Weaver DD, Jones SJ: Mutations in EZH2 cause Weaver syndrome. Am J Hum Genet 2012, 90:110-118.

24. Riviere JB, van Bon BW, Hoischen A, Kholmanskikh SS, O'Roak BJ, Gilissen C, Gijsen S, Sullivan CT, Christian SL, Abdul-Rahman OA, Atkin JF, Chassaing N, Drouin-Garraud V, Fry AE, Fryns JP, Gripp KW, Kempers M, Kleefstra T, Mancini GM, Nowaczyk MJ, van Ravenswaaij-Arts CM, Roscioli T, Marble M, Rosenfeld JA, Siu VM, de Vries BB, Shendure J, Verloes A, Veltman JA, Brunner $\mathrm{HG}$, et al: De novo mutations in the actin genes ACTB and ACTG1 cause Baraitser-Winter syndrome. Nat Genet 2012, 44:440-444.

25. Veeramah KR, O'Brien JE, Meisler MH, Cheng X, Dib-Haij SD, Waxman SG, Talwar D, Girirajan S, Eichler EE, Restifo LL, Erickson RP, Hammer MF: De novo pathogenic SCN8A mutation identified by whole-genome sequencing of a family quartet affected by infantile epileptic encephalopathy and SUDEP. Am J Hum Genet 2012, 90:502-510.

26. Cooper DN, Chen JM, Ball EV, Howells K, Mort M, Phillips AD, Chuzhanova N, Krawczak M, Kehrer-Sawatzki H, Stenson PD: Genes, mutations, and human inherited disease at the dawn of the age of personalized genomics. Hum Mutat 2010, 31:631-655.

\section{doi:10.1186/1479-7364-6-27}

Cite this article as: Ku et al:: A new era in the discovery of de novo mutations underlying human genetic disease. Human Genomics 2012 $6: 27$.

\section{Submit your next manuscript to BioMed Central and take full advantage of:}

- Convenient online submission

- Thorough peer review

- No space constraints or color figure charges

- Immediate publication on acceptance

- Inclusion in PubMed, CAS, Scopus and Google Scholar

- Research which is freely available for redistribution 